\title{
An epidemiological study on survival of oropharyngeal cancer cases in Alexandria, Egypt
}

\author{
N.K.R. Ibrahim, ${ }^{1}$ M.S. Al Ashakar, ${ }^{2}$ Z.M. Gad, ${ }^{3}$ M.H. Warda ${ }^{4}$ and H. Ghanem ${ }^{5}$
}

$$
\begin{aligned}
& \text { در اسة وبائية حول البقاء على قيد الحياة لحالات السرطان الفموي البلعومي في الإسكندرية، مصر }
\end{aligned}
$$

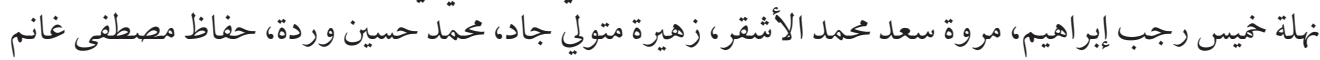

$$
\begin{aligned}
& \text { الخلاصسة: أجرى الباحثون دراسة أترابية استعادية للتعرف على البقاء على قيد الحياة لمدة } 5 \text { سنوات وعلى عو امل }
\end{aligned}
$$

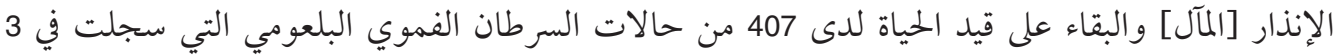

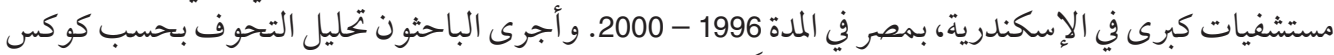

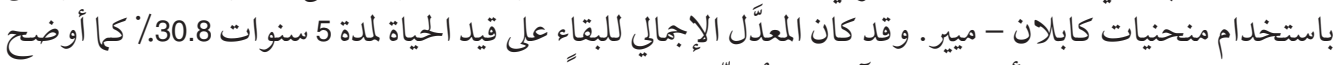

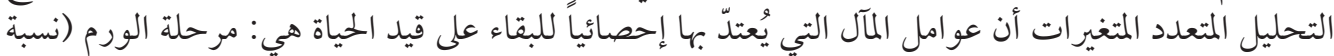

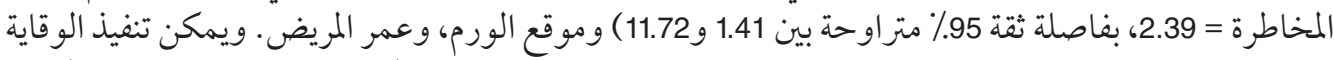

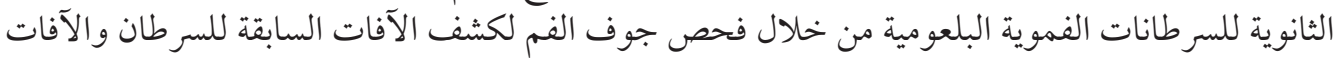

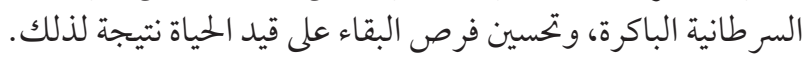

ABSTRACT A retrospective cohort study was conducted to determine the 5-year survival and prognostic factors for survival for 407 oropharyngeal cancer cases registered in the 3 main hospitals in Alexandria, Egypt, from 1996-2000. Survival analysis was conducted using Kaplan-Meier curves, and multivariate Cox regression analysis. The overall 5-year survival rate was $30.8 \%$. Multivariate analysis showed that significant prognostic factors for survival were tumour stage (hazard ratio $=2.39 ; 95 \% \mathrm{Cl}$ : 1.41-11.72), tumour site and patient's age. Secondary prevention of oral cancers can be conducted through examination of the oral cavity to find precancerous and early cancerous lesions and hence improve survival.

\section{Étude épidémiologique sur la survie des sujets atteints de cancer oropharyngé à Alexandrie (Égypte)}

RÉSUMÉ Une étude rétrospective de cohorte a été menée afin de déterminer la survie à 5 ans et les facteurs pronostiques de survie concernant 407 cas de cancer oropharyngé enregistrés dans les 3 principaux hôpitaux d'Alexandrie (Égypte) entre 1996 et 2000. L'analyse de survie a été réalisée à l'aide des courbes de Kaplan-Meier et du modèle de régression multivariée de Cox. Le taux global de survie à 5 ans était de 30,8\%. L'analyse multivariée a montré que le stade de la tumeur (rapport des risques instantanés [hazard ratio] = 2,39; IC $95 \%: 1,41-11,72$ ) et son emplacement, ainsi que l'âge du patient étaient des facteurs pronostiques de survie significatifs. La prévention secondaire des cancers de la bouche peut s'appuyer sur l'examen de la cavité buccale, qui permet de détecter des lésions précancéreuses et des cancers débutants, et d'améliorer ainsi la survie.

${ }^{1}$ Department of Family and Community Medicine, Faculty of Medicine, King Abdul-Aziz University, Jeddah, Saudi Arabia (Correspondence to N.K.R. Ibrahim: nahla_khamis@hotmail.com). ${ }^{2}$ Faculty of Dentistry; ${ }^{3}$ Department of Epidemiology, High Institute of Public Health; ${ }^{4}$ Department of Maxillo-Facial and Plastic Surgery, Faculty of Dentistry; ${ }^{5}$ Department of Clinical Oncology, Faculty of Medicine, Alexandria University, Alexandria, Egypt.

Received: 10/05/06; accepted: 03/09/06

المجلة الصحية لشرق المتوسط، منظمة الصحة العالمية، المجلد الخامس عشر، العلد Y، 9 +. 


\section{Introduction}

Although both oral and pharyngeal cancers are preventable, they remain a major challenge to all oral health programmes [1]. They are ranked as the 7th cause of mortality worldwide according to a World Health Organization (WHO) report in 1998, with an estimated global mortality of 260000 deaths [2], and accounted for approximately $2 \%$ of all cancer deaths in 2004 [3].

Oral cancer is a serious problem and causes high levels of morbidity and mortality in most areas of the world, a situation that has not improved in decades [4]. It constitutes $0.6 \%-5 \%$ of all human malignant tumours [5]. The prevalence of oral cancer is particularly high among men and is ranked as the 8 th most common cancer worldwide [1]. According to Parkin et al., the area in the world with the highest incidence of oral cancer was Melanesia (31.5 per 100000 in men and 20.5 per 100000 women) [6]. Differing incidence rates of oral cancer in different areas of the world reflect the differing prevalence of specific risk factors, such as use of tobacco, alcohol and betel quid. Mortality is on average less than half the incidence [6].

In Egypt in 1991 the adjusted death rates for malignant neoplasm of the lip, oral cavity and pharynx were 0.3 per 100000 person-years for males and 0.2 per 100000 person-years for females [7]. The clinical evolution of oral cancer has a bad prognosis, i.e. the 5-year survival rate ranges from $34 \%$ to $56 \%$ [5]. Little is known about the disease-specific cumulative survival rate and factors affecting it among patients with oropharyngeal cancer [8]. We therefore investigated the 5-year survival rate and prognostic factors of survival for oropharyngeal cancer in Alexandria, Egypt, from 1996-2000.

\section{Methods}

\section{Sample}

A retrospective cohort study was conducted over 18 months. The cohort comprised all oropharyngeal cancer cases registered over a 5 year period (January 1996 to December 2000) by 3 departments of the main hospitals responsible for diagnosing, treating and registering such cancers in Alexandria. The departments were the maxillofacial department in the Faculty of Dentistry, the oncology department in Alexandria's main University Hospital and the cancer registry of the Medical Research Institute. A search was made for cases of oropharyngeal cancer from all files of the 3 departments.

\section{Data collection}

The registers of oropharangeal cancer cases were reviewed to collect personal and clinical data about the site, size, histopathological type, grading and staging of the tumour. The clinical data were evaluated by means of the original pathology report and clinical description of the treatment.

Follow-up letters were sent to patients asking that they report to assigned clinics. Those who could not come were asked to explain. A few letters were received from the relatives of patients reporting their death and date of death. Home visits were made to patients who missed the follow-up. Cases were classified as alive, dead (date of death was recorded) or lost to follow-up (date of last visit was determined from the records).

The follow-up period, which was the period between the date of disease diagnosis and the last date of follow-up, was calculated in months for each patient.

\section{Statistical analysis}

The statistical analysis was done using SPSS, version 9. Survival of patients was 
computed for all cases known to follow-up as one group. The influence of study variables on survival was examined by univariate and multivariate analysis.

For univariate analysis, survival after diagnosis was estimated using the KaplanMeier procedure using the product limit method. The Kaplan-Meier method was based on the information available on each case, i.e. the period of follow-up of each patient in months. The probability of survival over a given length of time with many small intervals was calculated. The obtained estimates were expressed in graphical form drawn as a step function. The proportion surviving remained unchanged between events even if there were some intermediate censored observations.

The significance of the difference between survival curves was calculated by the $\log$ rank test of significance. $P$-values $<0.05$ were considered statistically significant.

Survival duration was also calculated by fitting data with multivariate Cox proportional hazard regression model (stepwise method) to control and adjust for all confounding factors. The confidence intervals (CI) for the hazard ratios (HR) were calculated.

\section{Results}

The study included 407 oropharyngeal cancer cases, with a mean age of 52.4 [standard deviation (SD) 16.0] years. Among all cancer cases, 120 cases $(29.5 \%)$ were alive, $120(29.5 \%)$ were dead, while 167 cases $(41.0 \%)$ were lost to follow-up. The cases showed a slight male predominance, with a male to female ratio of $1.4: 1$, although the difference was not statistically significant $(P>0.05)$.

Regarding the site of the neoplasm, $58.8 \%$ were intraoral and $41.2 \%$ were extraoral. The most frequently affected site was the tongue $(19.2 \%)$, followed by the cheek (15.2\%) and lip (13.0\%). About twothirds $(62.8 \%)$ of the oropharyngeal cancer cases were squamous cell carcinoma.

The survival time of the study cohort ranged from 36-46 months with a mean of 42 (SD 40.4) months. The cumulative 12 -month survival rate was $76.5 \%$, falling to $30.8 \%$ for the 5 -year survival at the end of the study period (Table 1).

\section{Survival rates by demographic factors}

It is evident from Table 1 that age was significantly associated with survival of patients with oropharangeal cancer. The highest 5-year survival rate $(50.0 \%)$ was for those aged $<30$ years at the time of diagnosis, followed by those aged 30-60 years $(42.0 \%)$. The survival rate reached $0 \%$ among those aged $60+$ years (log rank test $=6.02 ; P<0.05)$.

Regarding the influence of sex on the prognosis of orofacial cancer, the survival of males $(28.3 \%)$ was lower than females (34.8\%). However, no significant difference was found between the 2 groups (log rank $=0.02 ; P>0.05$ ).

Also, there was no statistically significant difference in 5-year survival rates between those living in urban $(33.9 \%)$ and rural areas $(29.7 \%)(\log \operatorname{rank}=0.04 ; P>$ $0.05)$

\section{Survival rates by site and type of tumour}

The 5-year survival rate (Kaplan-Meier) was statistically significantly much greater for extraoral tumours (48.3\%) compared to intraoral sites $(20.8 \%)$ (log rank test $=$ 12.32; $P<0.05$ ) (Figure 1).

The results revealed that patients with lip cancer had the best survival $(73.6 \%)$, followed by parotid gland (58.4\%), gingiva $(51.2 \%)$ and retromolar cancers $(50.8 \%)$. 
Table 1 Five-year survival rate of oropharyngeal cancer cases in Alexandria according to age at diagnosis

\begin{tabular}{|c|c|c|c|c|c|c|c|c|}
\hline \multirow[t]{2}{*}{$\begin{array}{l}\text { Age } \\
\text { (years) }\end{array}$} & \multirow{2}{*}{$\begin{array}{c}\text { Total } \\
\text { cases } \\
\text { No. }\end{array}$} & \multicolumn{2}{|c|}{ Deaths } & \multicolumn{2}{|c|}{$\begin{array}{l}\text { Censored } \\
\text { cases }\end{array}$} & \multirow{2}{*}{$\begin{array}{c}\begin{array}{c}\text { Survival time } \\
\text { (months }\end{array} \\
\text { Mean (SD) }(95 \% \mathrm{Cl})\end{array}$} & \multirow{2}{*}{$\begin{array}{c}\text { Cumulative } \\
\text { 12-month } \\
\text { survival } \\
\%\end{array}$} & \multirow{2}{*}{$\begin{array}{c}\text { Cumulative } \\
5 \text {-year } \\
\text { survival } \\
\% \\
\end{array}$} \\
\hline & & No. & $\%$ & No. & $\%$ & & & \\
\hline$<30$ & 41 & 11 & 26.8 & 30 & 73.2 & 38 (38.4) (26-49) & 72.9 & 50.0 \\
\hline $31-60$ & 240 & 67 & 27.9 & 173 & 72.1 & 45 (31.0) (40-49) & 80.9 & 42.0 \\
\hline 60 & 126 & 42 & 33.3 & 84 & 66.7 & 35 (44.9) (28-42) & 68.5 & 0.0 \\
\hline All cases & 407 & 120 & 29.5 & 287 & 70.5 & $42(40.4)(38-46)$ & 76.5 & 30.8 \\
\hline
\end{tabular}

Log rank test $=6.02 ; P<0.05$.

$S D=$ standard deviation $\mathrm{Cl}=$ confidence interval.

Poor survival was documented for tumours of the mandible, minor salivary glands, tonsils and floor of the mouth. These differences were statistically significant (log rank test $=28.07 ; P<0.05$ )

The survival rates differed statistically significantly according to the histopatho- logical types of tumour. The best 5-year survival rate in the present study was for basal cell carcinoma $(100 \%)$ followed by salivary gland tumour $(64.9 \%)$ while the lowest survival $(29.5 \%)$ was for patients with squamous cell carcinoma (log rank test $=19.11 ; P<0.05)$.

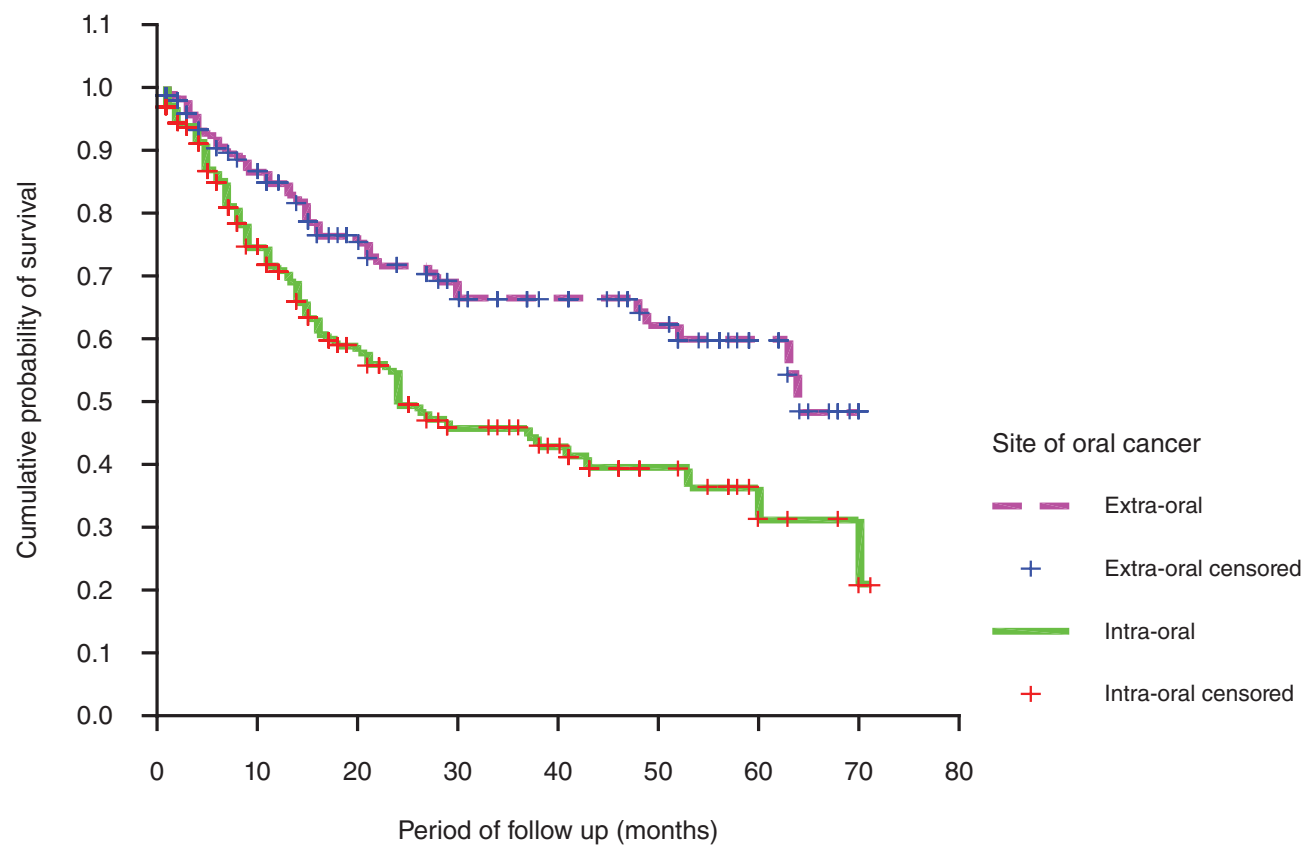

Figure 1 Kaplan-Meier survival curve for oropharyngeal cancer cases in Alexandria, according to site of tumour $(\log$ rank test $=12.32 ; P<0.05)$ 
The results showed that the best survival of oropharyngeal cancers was for those with well-differentiated tumours compared to those with moderately and poorly differentiated types and there was a statistically significance difference between the 3 groups $(\log$ rank $=6.59 ; P<0.05)$.

The survival rate was much lower among patients with lymph node involvement compared to other patients. About $60 \%$ difference in survival was noticed between patients with positive lymph nodes compared to those with negative lymph node (log rank test $=29.47 ; P=0.000)$ (Figure 3).

\section{Survival rates by stage of tumour}

Table 2 shows that the 5-year survival rates were inversely proportional to the stage of tumour; the rates were 100\%, 65.6\%, 42.0\% and $0 \%$ for patients in stage I, II, III and IV respectively. These differences were highly statistically significant $(\log$ rank $=63.50 ; P$ $<0.001)$.

Kaplan-Meier analysis showed that patients who presented with localized stage (stage I and stage II) had a higher probability of survival than those presenting with advanced stage (stage III and stage IV) (Figure 2). The mean survival time was 63 (SD 19.9) months and 30 (SD 43.3) months for the localized and advanced stages respectively (log rank test $=47.81$; $P<0.001)$.

\section{Predictors of survival}

Multivariate Cox regression analysis (Table 3 ) showed the factors that remained significant predictors of survival after controlling of all confounding variables. The first predictor of oropharyngeal cancer survival was staging of tumour. Those with advanced stages (stage III, IV) were at 2.39 times increased risk of death compared to those with localized stages I (stage I, II). The second predictor was the site of tumour; those with intraoral site had about 2 times increased risk of death compared to those with extraoral tumours $(\mathrm{HR}=1.81 ; 95 \%$ CI: 1.19-4.01).

\section{Discussion}

Oral and pharyngeal cancer survival rates are relatively little studied but it is known that a patient's chance of survival is improved significantly with early detection and treatment [9]. The results of our study showed that male cases prevailed over females (1.4:1), and the tongue was the most frequent site of oropharyngeal cancers.

Table 2 Five-year survival rate of oropharyngeal cancer cases in Alexandria according to clinical stage

\begin{tabular}{|c|c|c|c|c|c|c|c|c|}
\hline \multirow[t]{2}{*}{$\begin{array}{l}\text { Clinical } \\
\text { stage }\end{array}$} & \multirow{2}{*}{$\begin{array}{c}\text { Total } \\
\text { cases } \\
\text { No. }\end{array}$} & \multicolumn{2}{|c|}{ Deaths } & \multicolumn{2}{|c|}{$\begin{array}{c}\text { Censored } \\
\text { cases }\end{array}$} & \multirow{2}{*}{$\begin{array}{c}\text { Survival time in } \\
\text { months } \\
\text { Mean (SD) (95\% Cl) }\end{array}$} & \multirow{2}{*}{$\begin{array}{l}\text { Cumulative } \\
\text { 12-month } \\
\text { survival } \\
\% \\
\end{array}$} & \multirow{2}{*}{$\begin{array}{c}\text { Cumulative } \\
\text { 5-year } \\
\text { survival } \\
\% \\
\end{array}$} \\
\hline & & No. & $\%$ & No. & $\%$ & & & \\
\hline | & 29 & 0 & 0.0 & 29 & 100.0 & - & 100.0 & 100.0 \\
\hline II & 67 & 7 & 10.5 & 60 & 89.6 & $61(24.6)(55-67)$ & 89.5 & 65.6 \\
\hline III & 121 & 40 & 33.1 & 81 & 66.9 & 38 (44.0) (31-45) & 69.2 & 42.0 \\
\hline IV & 89 & 43 & 48.3 & 46 & 51.7 & 20 (28.3) (15-25) & 56.5 & 0.0 \\
\hline All cases & 306 & 90 & 29.4 & 216 & 70.6 & $42(40.4)(38-46)$ & 76.5 & 30.8 \\
\hline
\end{tabular}

Log rank test $=63.50 ; \mathrm{P}<0.001$.

$S D=$ standard deviation; $\mathrm{Cl}=$ confidence interval.

المجلة الصحية لشرق المتوسط، منظمة الصحة العالمية، المجلد الخامس عشر، العدد ب، 9 +. 


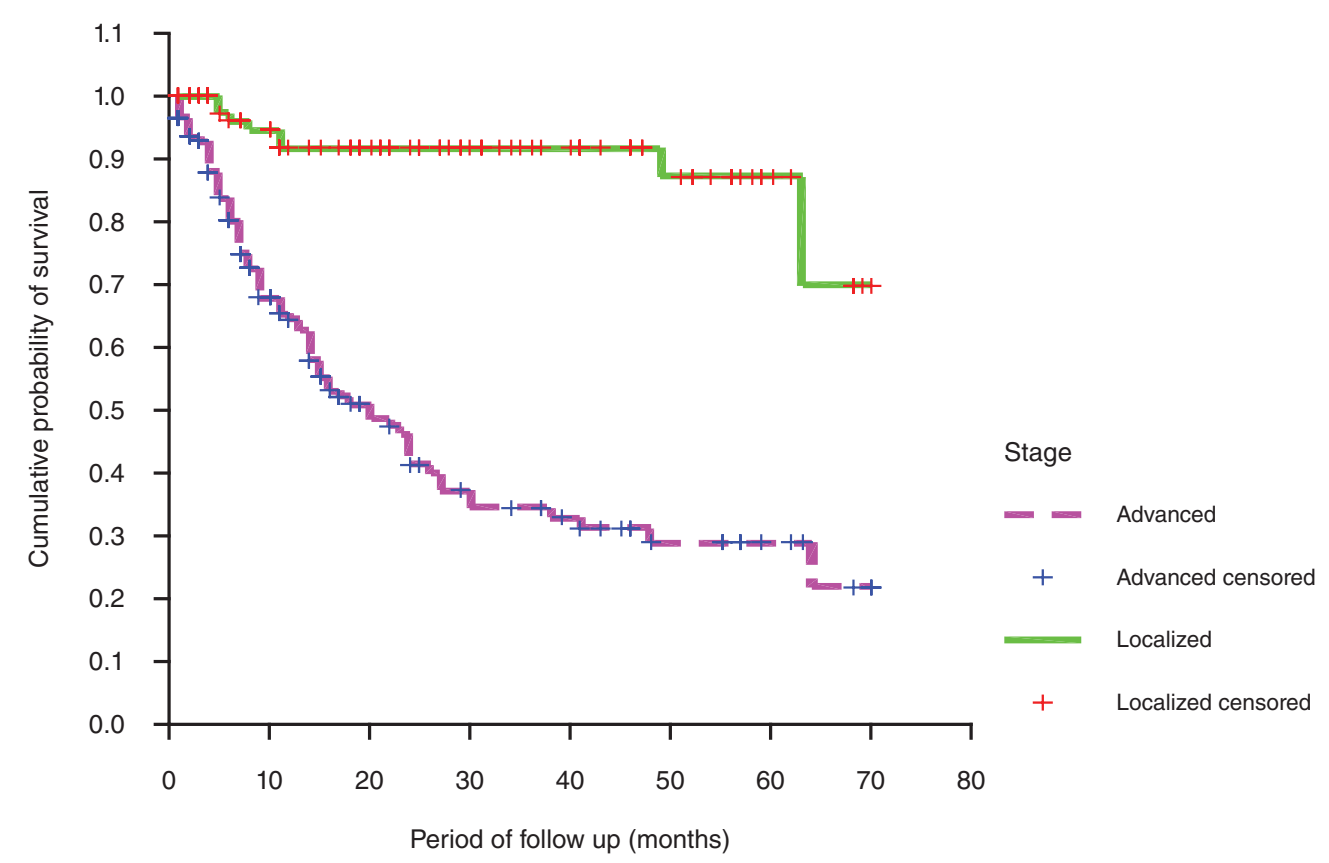

Figure 2 Kaplan-Meier survival curve for oropharyngeal cancer cases in Alexandria, according to the tumour stage (log rank test $=47.81 ; P<0.001)$

This result concurs with results of 2 studies reported from Argentina in 2005 [5] and 2006 [4].

A low 5-year survival rate of oropharyngeal cancer cases $(30.8 \%)$ was found in the our study. A similar figure was obtained from an older study of oropharyngeal cancer from Germany (32\%) [10]. On the other hand, higher rates have been obtained from results of a meta-analysis in Argentina (39\%) [5], and from Italy (43.9\%) [11] and the United State of America (USA) (56\%) [12]. The wide discrepancy in survival rates of these studies compared to our study may be due to better screening with early detection of cases, and advances in diagnosis and therapeutic modalities that lead to early discovery and treatment of patients which could boost survival and reduce morbidity and mortality [13].
Our study showed that the 5-year survival rate from oropharyngeal cancer was directly related to age. This agrees with studies from Chicago, USA in 2005 [14], Taiwan in 2004 [15] and Spain in 2002 [16].

In Italy, Carini et al. demonstrated that the closer the tumour origin to the inner sites of the mouth, the lower the survival rate [17]. This result agrees with ours; the survival rates were $20.8 \%$ and $48.3 \%$ for intraoral and extraoral sites respectively. The best survival rate in our study was with lip cancer; this concurs with the result of Yeole et al. in India [18]. This may be because lip cancer is noticed early by the patients and so they seek early diagnosis and treatment before it reaches an advanced stage.

Our findings demonstrate poor survival rate for patients with squamous cell carcinoma $(29.5 \%)$; the best prognosis of $100 \%$ 
Table 3 Cox regression for oropharyngeal cancer cases in Alexandria (1996-2000)

\begin{tabular}{lcccc}
\hline Variable & $\mathbf{B}$ & $\mathbf{S E}_{(\mathbf{B})}$ & HR & $\mathbf{9 5 \%} \mathbf{C l}$ \\
\hline Staging (advanced) & 0.913 & 0.902 & 2.39 & $1.41-11.72$ \\
Site (intraoral) & 0.213 & 0.648 & 1.81 & $1.19-4.01$ \\
Per year increase in age & 0.059 & 0.312 & 1.06 & $1.01-1.13$
\end{tabular}

$B=$ regression coefficient $; S E=$ standard error; $H R=$ hazard ratio; $C l=$ confidence interval .

was for basal cell carcinoma. This result differs from that of Oliver et al. in the USA who found no correlation between the oral cancer and its histopathological type [19].

Herrera et al. found that the presence of lymph node metastasis was one of the most important prognostic factors in oral cancer [20]. Our findings showed that the 5 -year survival rates for oropharyngeal cancer were $85.3 \%$ and $25.0 \%$ in the groups without $(\mathrm{N}-)$ and with $(\mathrm{N}+)$ lymph node involvement respectively. Results of a study conducted among patients with oral cancer in Jordan agree with ours; their corresponding figures were $87 \%$ and $17 \%$ respectively [21]. Noguchi et al. reported rates of $91 \%$ and $41 \%$ for Japanese patients in $\mathrm{N}-$ and $\mathrm{N}+$ groups respectively [22]. The higher figures obtained from the Japanese study may be attributed to the early diagnosis of oral cancer and the advances in treatment approaches.

Several studies have demonstrated an inverse relationship between advanced tumour stage and patient survival, which

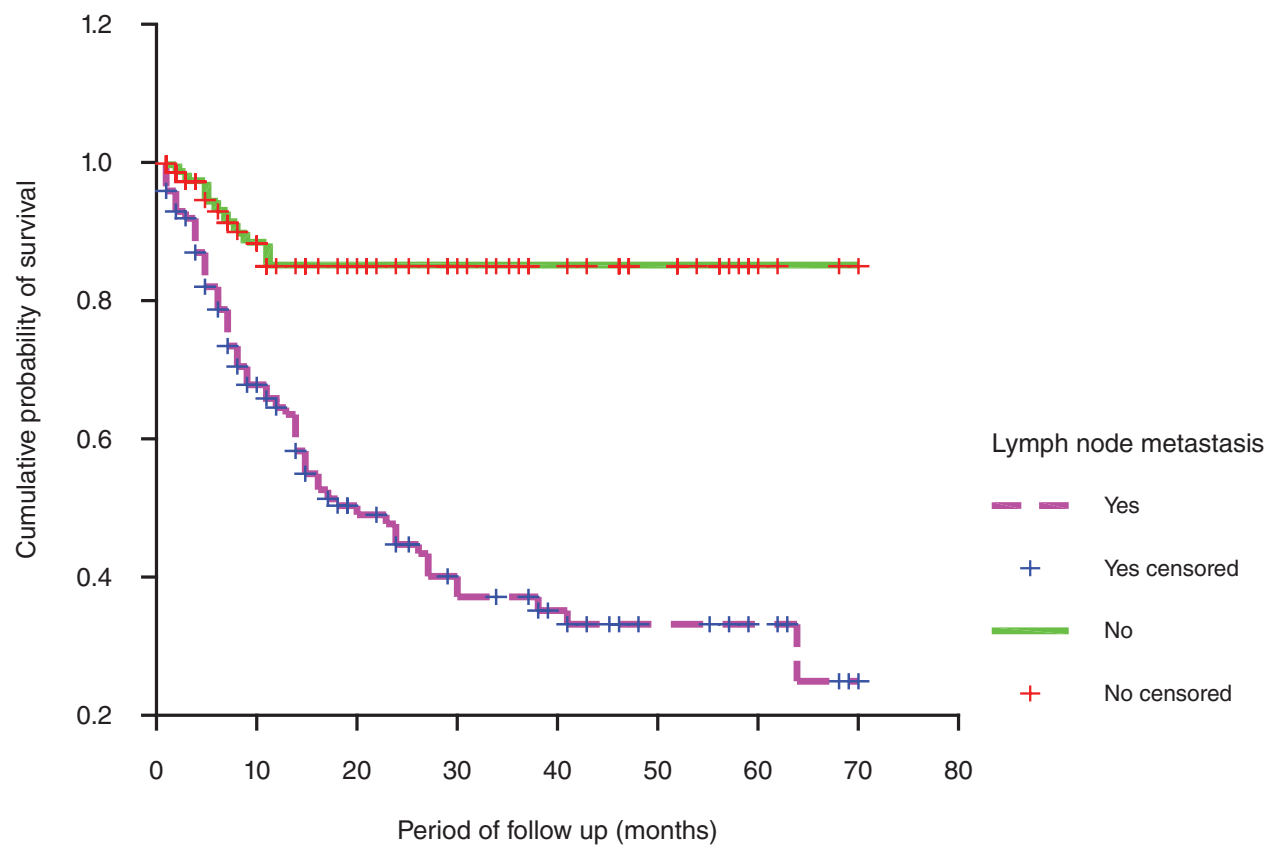

Figure 3 Kaplan-Meier survival curve for oropharyngeal cancer cases in Alexandria, according to lymph node involvement $(\log$ rank $=29.47 ; P<0.001)$

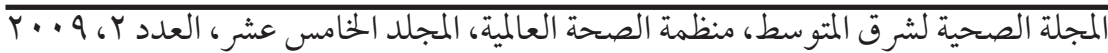


agrees with our results $[8,12,23,24]$. In our study, the 5 -year survival rates were $100 \%, 65.6 \%, 42.0 \%$ and $0 \%$ for patients in stage I, II, III and IV respectively, which is similar (except for stage IV) to that obtained from a Brazilian study with rates of $76.7 \%$, $64.4 \%, 44.8 \%$ and $25.5 \%$ for the 4 stages respectively [23]. However, our results are much lower than those obtained from 2 studies that investigated the outcomes of oral squamous cell carcinoma after surgical therapy in Taiwan [24] and Australia [8].

Several studies have shown poor survival for advanced stages (III, IV) of oral cancer compared with localized stages (stages I, II) [20,25]. This agrees with our results where survival was much better for localized $(69.7 \%)$ compared to advanced tumours $(21.2 \%)$.

Multivariate analysis showed significant prognostic values for 3 factors: staging of tumour, site of tumour and patient's age. Varela-Centelles et al. found that independent prognostic values for oral cancer in Spain were patient's age, tumour size and stage [16], while Kademani et al. in the USA [12] reported that grade and stage were independent factors in predicting survival in patients with oral squamous cell carcinoma.
Our study was a hospital-based not a population based study. It therefore probably does not represent the totality of cases of oropharyngeal cancer in Alexandria.

\section{Conclusion}

Poor survival rates of oropharyngeal cancers were recorded in the present study. Advanced tumour stage (due to delay in seeking medical treatment) was found to be the most important predictor of poor survival, suggesting that the patient's chance of survival may be improved with early detection and treatment of the tumour. Therefore efforts should be made to improve the rate of early detection, perhaps through public education and screening for oral cancer by examination of the oral cavity, especially for high-risk groups.

\section{Acknowledgements}

The authors would like to thank all those who facilitated the accomplishment of this work and to thank also all patients who participated in the study.

\section{References}

1. Petersen PE. World oral health report 2003. Continuous improvement of oral health in the 21st century - the approach of the WHO Global Oral Health Program. Geneva, World Oral Health, 2003 (WHO/ $\mathrm{NMH} / \mathrm{NPH} / \mathrm{ORH} / 03.2)$.

2. Chapter 2: Measuring health. In: The world health report 1998. Life in the 21st century: a vision for all. Geneva, World Health Organization, 1998.

3. Gorsky $\mathrm{M}$ et al. Carcinoma of the tongue: a case series analysis of clinical presentation, risk factors, staging, and outcome.
Oral surgery, oral medicine, oral pathology, oral radiology, and endodontics, 2004, 98(5):546-52.

4. Morelatto RA et al. Oral cancer mortality in the province of Cordoba, Argentine Republic in the period 1975-2000. A comparative study with other populations. Medicina oral, patología oral y cirug ía bucal, 2006, 11(3):E230-5.

5. Brandizzi D et al. Analysis of the epidemiological features of oral cancer in the city of Buenos Aires. Acta odontológica latinoamericana, 2005, 18(1):31-5. 
6. Parkin DM et al. Global cancer statistics, 2002. CA: a cancer journal for clinicians, 2005, 55:74-108.

7. World health statistics annual 1998. Geneva, World Health Organization, 1998.

8. Chandu A et al. Factors affecting survival in patients with oral cancer: an Australian perspective. International journal of oral and maxillofacial surgery, 2005, 34(5):514-20.

9. Logan HL. Effectiveness of a community based oral cancer prevention campaign. Florida, Health Services and Research Unit of Florida, 2003.

10. Knöbber D et al. Vorbestrahlung und Operation von Patienten mit einem Plattenepithelkarzinom der Mundhohle und des Oropharynx: Ergebnisse einer Studie 1973 bis 1984. [Pre-irradiation and surgery of patients with squamous cell carcinoma of the oral cavity and pharynx: the results of a 1973-1984 study.] Strahlentherapie und Onkologie, 1987, 163(11):706-13.

11. Carini F et al. A comparison between TNM and TANIS stage grouping for predicting prognosis of oral and oropharyngeal cancer. Journal of oral and maxillofacial surgery, 1998, 56(7):823-7.

12. Kademani $D$ et al. Prognostic factors in intraoral squamous cell carcinoma: the influence of histologic grade. Journal of oral and maxillofacial surgery, 2005, 63(11):1599-605.

13. Mathew B et al. Evaluation of mouth selfexamination in the control of oral cancer. British journal of cancer, 1995, 71:397-9.

14. Epstein JB et al. Patients with oropharyngeal cancer: a comparison of adults living independently and patients living in long-term care facilities. Special care in dentistry, 2005, 25(2):124-30.

15. Chen PH et al. Important prognostic factors of long-term oropharyngeal carcinoma survivors in Taiwan. Oral oncology, 2004, 40(8):847-55.
16. Varela-Centelles PI et al. Survival to oral cancer. A study of clinical risk markers with independent prognostic value. Bulletin du Groupement international pour la recherche scientifique en stomatologie \& odontologie, 2002, 44(2):46-51.

17. Carini $F$ et al. Site-dependent survival in cancer of the oral cavity. Journal of craniofacial surgery, 1997, 8(5):399-404.

18. Yeole BB et al. Survival from head and neck cancer in Mumbai (Bombay), India. Cancer, 2000, 89:437-44.

19. Oliver AJ et al. Primary oral squamous cell carcinoma: a review of 92 cases Journal of oral and maxillofacial surgery, 1996, 54(8):949-55.

20. Muñoz Herrera A et al. Supervivencia en el carcinoma epidermoide de cavidad oral. [Survival rate in epidermoid carcinoma of the oral cavity.] Acta otorrinolaringológica española, 2001, 52(5):381-6.

21. Ma'aita JK. Oral cancer in Jordan: a retrospective study of 118 patients. Croatian medical journal, 2000, 41(1):64-9.

22. Noguchi $M$ et al. Prognostic factors and relative risk for survival in N 1-3 oral squamous cell carcinoma: a multivariate analysis using Cox's hazard model. British journal of oral and maxillofacial surgery, 1999, 37(6):433-7.

23. De Cássia Braga Ribeiro K, Kowalski LP, Latorre MdO R. Perioperative complications, comorbidities, and survival in oral or oropharyngeal cancer. Archives of otolaryngology, head \& neck surgery, 2003, 129(2):219-28.

24. Lo WL et al. Outcomes of oral squamous cell carcinoma in Taiwan after surgical therapy: factors affecting survival. Journal of oral and maxillofacial surgery, 2003, 61(7):751-8.

25. Gervasio OL et al. Oral squamous cell carcinoma: a retrospective study of 740 cases in a Brazilian population. Brazilian dental journal, 2001, 12(1):57-61. 